\title{
Anti-inflammatory steroid signalling in the human peritoneum
}

\author{
K S Fegan, M T Rae ${ }^{1}$, H O D Critchley ${ }^{1}$ and S G Hillier ${ }^{1}$ \\ University of Edinburgh Cancer Research Centre, Crewe Road South, Edinburgh EH4 2XR, UK \\ ${ }^{1}$ Queen's Medical Research Institute, Centre for Reproductive Biology, University of Edinburgh, 47 Little France Crescent, Edinburgh EH16 4TJ, UK \\ (Correspondence should be addressed to S G Hillier; Email: s.hillier@ed.ac.uk)
}

(M T Rae is now at School of Life Sciences, Napier University, Craiglockhart Campus, Edinburgh EH14 1DJ, UK)

\begin{abstract}
Peritoneal surface epithelial (PSE) cells participate in adhesion formation following inflammatory injury yet adjacent ovarian SE (OSE) cells regenerate without scarification after ovulation. OSE cells show inflammation-associated expression of $11 \beta$ hydroxysteroid dehydrogenase type 1 (11ßHSD1) enzyme, enabling intracrine generation of anti-inflammatory cortisol to minimise tissue damage. We asked if human PSE cells show an $11 \beta$ HSD1 response to pro-/anti-inflammatory stimulation and if so, how the 11-oxoreductase activity generated compares with OSE. PSE collected from premenopausal women undergoing surgery for benign gynaecological conditions were used to establish primary PSE cell cultures that were treated for $48 \mathrm{~h}$ with interleukin-1 $\alpha$ (IL-1 $\alpha$ ) with/without anti-inflammatory steroid (cortisol or progesterone). mRNA levels corresponding to the genes of interest (11ßHSD1, 11ßHSD2, cyclooxygenase-2, COX-2) were measured by quantitative

RT-PCR. IL- $1 \alpha \quad(0.5 \mathrm{ng} / \mathrm{ml})$ stimulated $11 \beta \mathrm{HSD} 1$ and COX-2 mRNA levels in PSE cells but 11ßHSD2 was unaffected. Cortisol $(1 \mu \mathrm{M})$, not progesterone $(1 \mu \mathrm{M})$, increased 11ßHSD1 mRNA and synergistically enhanced IL- $1 \alpha$ action. Cortisol suppressed IL- $1 \alpha$-stimulated COX-2 more effectively than progesterone. PSE cells had a significantly lower basal 11-oxoreductase enzyme activity than OSE cells; IL- $1 \alpha$ did not significantly increase the 11-oxoreductase activity in PSE cells but did so in OSE cells. We conclude that PSE cells respond to IL- $1 \alpha$ and antiinflammatory steroids in qualitatively similar ways as OSE. However, the enzymatic activity of $11 \beta \mathrm{HSD} 1$ is lower in PSE and less responsive to IL- $1 \alpha$. This could help explain why peritoneal healing often leads to adhesion formation, whereas postovulatory ovarian healing is scar-free.

Journal of Endocrinology (2008) 196, 369-376
\end{abstract}

\section{Introduction}

An emerging theme in inflammation research is that inflammatory stimuli regulate genes that localise and limit potentially damaging cellular responses. When this machinery fails, pathological sequelae ensue. One such 'anti-inflammatory' gene is HSD11B1, encoding $11 \beta$ hydroxysteroid dehydrogenase type 1 (11ßHSD1), a steroidogenic enzyme that metabolises cortisone to cortisol through its 11-oxoreductase enzymatic activity. The activity of $11 \beta \mathrm{HSD} 1$ is offset by $11 \beta \mathrm{HSD} 2$, the encoded product of HSD11B2 that back converts cortisol to cortisone. Since cortisol - but not cortisone - binds glucocorticoid receptor (GR) and activates downstream antiinflammatory signalling, relative levels of $11 \beta \mathrm{HSD} 1$ and $11 \beta \mathrm{HSD} 2$ potentially set local inflammatory tone (Draper \& Stewart 2005). Differentially expressed $11 \beta$ HSD 1 and $11 \beta \mathrm{HSD} 2$ in a naturally inflamed tissue was first observed in human ovary approaching ovulation. Ovulation bears vascular, haemodynamic and biochemical hallmarks of inflammation, and granulosa cells from periovulatory follicles selectively express 11ßHSD1 mRNA over 11ßHSD2 mRNA (Tetsuka et al. 1997). From work on renal mesangeal cells it emerged that inflammatory cytokines such as interleukin- $1 \alpha(\mathrm{IL}-1 \alpha)$ and tumour necrosis factor $\alpha$ directly stimulate $11 \beta \mathrm{HSD} 1$ and suppress $11 \beta \mathrm{HSD} 2$ activities in vitro (Escher et al. 1997). This is now known to hold for several other cell types that naturally respond to inflammatory signals, including ovarian granulosa (Tetsuka et al. 1999) and surface epithelial cells (Yong et al. 2002), bronchial epithelial cells (Feinstein \& Schleimer 1999), preadipocytes (Tomlinson et al. 2001), osteoblasts (Cooper et al. 2001), aortic smooth muscle cells (Cai et al. 2001), peritoneal macrophages (Gilmour et al. 2006), trophoblast (Li et al. 2006) and fetal membranes (Sun \& Myatt 2003).

At the ovarian level, cortisol generated through intracrine $11 \beta H S D$ signalling potentially contributes to the natural injuryrepair process associated with ovulation. In particular, the ovarian surface epithelium (OSE), which is contiguous with the peritoneal SE (PSE), undergoes serial inflammation-associated injury and repair with each follicular rupture (Rae \& Hillier 2005). We have previously shown that OSE cells express $11 \beta \mathrm{HSD} 1 \mathrm{mRNA}$ and 11-oxoreductase enzyme activity catalysed by the encoded 11ßHSD1 protein (Yong et al. 2002). We have also shown that IL- $1 \alpha$-induced experimental 'inflammation' of OSE cells measured as an increased expression of cyclooxygenase-2 (COX-2) is suppressed by cortisol and to a lesser extent progesterone (Rae et al. 2004). Both cortisol and 
progesterone are anti-inflammatory steroids that act via nuclear GR and progesterone (PR) receptors in target cells to repress pro-inflammatory transcription factors such as nuclear factor $\kappa$ B and activating protein-1 (van der Burg \& van der Saag 1996, Rhen \& Cidlowski 2005). Since micromolar concentrations of cortisol and progesterone accumulate in follicular fluid at ovulation (Andersen 1991, Andersen \& Hornnes 1994), either or both might participate in postovulatory ovarian healing and act on adjacent PSE.

The mesothelial cells lining the peritoneal surface are also potential glucocorticoid and progesterone targets and are inevitably exposed to high concentrations of follicular steroids following follicular rupture. Interestingly, when postovulatory OSE repairs it does so rapidly without scarification or involving i.p. adhesions. On the other hand, inflammatory injury to the PSE frequently leads to adhesion formation with adverse clinical sequelae including pain, bowel obstruction and, in the female, infertility. Thus, despite their common embryological origin, the anti-inflammatory machineries of PSE and OSE cells likely differ. Here, we describe a simple method to collect and culture human PSE cells, based on the one we have previously used to study human OSE cells (Hillier et al. 1998, Auersperg et al. 2001). Using this culture system, we define interactions between an inflammatory cytokine (IL-1 $\alpha$ ) and two anti-inflammatory steroids (cortisol and progesterone) on $11 \beta \mathrm{HSD} 1,11 \beta \mathrm{HSD} 2$ and COX-2 mRNA expression in PSE cells in vitro. We also compare basal and cytokine-responsive 11-oxoreductase activities of PSE and OSE cells. Our results define properties of PSE cells that differ from OSE, which could bear on the particular way in which the peritoneum responds to inflammation and becomes involved in gynaecological disease states in vivo.

\section{Materials and Methods}

\section{Patients}

Samples of PSE were obtained at the time of surgery from premenopausal women undergoing surgery for benign gynaecological conditions. OSE cells for comparative purposes were also obtained from a subset of patients. All participants gave informed consent and the Local Research Ethics Committee approved the study. Relevant clinical details of the patients who donated cells are shown in Table 1. Patients with endometriosis or overt signs of peritoneal pathology were excluded from study.

\section{Collection and culture of PSE cells}

The method for PSE collection and culture was similar to that previously described for OSE (Hillier et al. 1998). The culture medium was Medium 199:MCDB 105 (1:1, v/v) supplemented with fetal calf serum $(15 \% \mathrm{v} / \mathrm{v})$, penicillin $(50 \mathrm{IU} / \mathrm{ml})$, streptomycin $(50 \mu \mathrm{g} / \mathrm{ml})$ and L-glutamine $(2 \mathrm{mmol} / \mathrm{l})$, all from Sigma-Aldrich Company Ltd. Briefly, the peritoneum was gently brushed using a sterile Aylesbury spatula or cytobrush (Cook Ireland Ltd, Limerick, Ireland) and then rinsed into prewarmed culture medium. Two sites were chosen for sampling PSE cells: the anterior abdominal wall, which has no contact with the OSE or pelvic organs, and the uterine fundus. The purpose of using these two sites was to determine whether the Müllerian source of PSE behaves in a manner similar to cells sourced from the non-Müllerian abdominal wall. The medium used to collect cells was transferred to $75 \mathrm{~cm}^{2}$ plastic tissue culture flasks (Corning BV Life Sciences, Schiphol-Rijk,

Table 1 Relevant clinical details of patients donating peritoneal surface epithelial (PSE) cells from which cultures were established and measurements obtained

\begin{tabular}{|c|c|c|c|c|c|c|}
\hline & Parity & Contraception & Day of cycle & Surgery & Indication for surgery & Measurement \\
\hline \multicolumn{7}{|c|}{ Age (year) } \\
\hline 38 & $1+2$ & DMPA & NA & Lap Ster & Unwanted fertility & mRNA \\
\hline 40 & $3+0$ & Fem Ster & 2 & TAH & $\mathrm{HMB}$ & mRNA \\
\hline 42 & $0+1$ & None & $?$ & $\mathrm{TAH}$ & HMB, dysmen & mRNA \\
\hline 50 & $2+0$ & None & 11 & TAH\&BSO & HMB, fibroids & mRNA \\
\hline 33 & $0+0$ & None & 19 & Diag Lap & Pelvic pain, dyspareunia & mRNA \\
\hline 25 & $0+1$ & None & $?$ & Diag Lap & Pelvic pain & mRNA \\
\hline 31 & $0+0$ & COCP & NA & Diag Lap & Pelvic pain, dyspareunia & mRNA \\
\hline 39 & $1+0$ & None & 5 & TAH & $\mathrm{HMB}$, dysmen & mRNA \\
\hline 34 & $2+0$ & Fem Ster & 27 & LAVH & HMB, dysmen & mRNA \\
\hline 47 & $2+0$ & LNG-IUS & NA & TAH\&BSO & Irreg bleeding, fibroids & mRNA \\
\hline 48 & $3+0$ & Fem Ster & 2 & $\mathrm{TAH}$ & HMB, fibroids & mRNA \\
\hline 43 & $2+0$ & Barrier & $?$ & Lap Ster & Unwanted fertility & 11-oxo-reductase \\
\hline 29 & $3+0$ & None & 13 & Diag Lap & Dyspareunia & 11-oxo-reductase \\
\hline 22 & $1+0$ & DMPA & NA & $\begin{array}{l}\text { Lap ovarian } \\
\text { cystectomy }\end{array}$ & Benign ovarian cyst & 11-oxo-reductase \\
\hline 28 & $0+0$ & СОCP & NA & Diag Lap & Pelvic pain, dyspareunia & 11-oxo-reductase \\
\hline
\end{tabular}

Parity is defined in $x+y$ format indicating number of pregnancies over 24 weeks $(x)+$ number of pregnancies failing to reach 24 weeks $(y)$.

NA, not applicable; ?, uncertain; DMPA, depo-medroxyprogesterone acetate; Fem Ster, female sterilisation; COCP, combined oral contraceptive pill; LNG-IUS, levonorgestrel intra-uterine system; Lap Ster, laparoscopic sterilisation; TAH, total abdominal hysterectomy; BSO, bilateral salpingo-oophorectomy; Diag Lap, diagnostic laparoscopy; HMB, heavy menstrual bleeding; dysmen, dysmenorrhoea. 
The Netherlands) precoated with donor calf serum. Each flask was examined by phase-contrast microscopy to verify that sufficient cellular material had been obtained. Cultures were then established by incubating the flasks at $37^{\circ} \mathrm{C}$ in a humidified atmosphere of $5 \% \mathrm{CO}_{2}$ and $95 \%$ air for up to 42 days. The flasks were inspected regularly, with medium renewal every 7 days.

\section{Experimental treatment of PSE cultures}

Confluent cell monolayers were washed twice with PBS prior to incubation in $1 \times$ Trypsin/EDTA solution (Invitrogen) for $5 \mathrm{~min}$ at $37^{\circ} \mathrm{C}$. Dissociated cells were then aspirated and sedimented by centrifugation for $5 \mathrm{~min}$ at $800 \mathrm{~g}$. The resulting cell pellet was resuspended in $2 \mathrm{ml}$ culture medium. Cell number and viability were estimated using a haemocytometer and vital staining with Trypan Blue (Sigma-Aldrich). To provide cell monolayers for immunohistochemical assessment (see below), PSE cells were seeded into eight-well chamber slides (VWR, Batavia, IL, USA) at a density of $5-10 \times 10^{4}$ cells $/ 0.5 \mathrm{ml}$ medium and incubated at $37^{\circ} \mathrm{C}$ overnight. For experiments involving hormone treatment and subsequent analysis of effect, cells were distributed into six-well plates (Corning) at a density of $4-5 \times 10^{5}$ cells $/ 0.5 \mathrm{ml}$ medium (for mRNA analysis) or 12 -well plates at a density of $2 \times 10^{5}$ cells $/ 0.5 \mathrm{ml}$ medium (for 11 -oxoreductase analysis). The medium was then aspirated and replaced with serum-free culture medium, containing 0 $01 \%$ BSA (Sigma-Aldrich). IL-1 $\alpha$ (R\&D Systems Europe Ltd, Abingdon, Oxon, UK) was diluted in serum-free medium to a final concentration of $0.5 \mathrm{ng} / \mathrm{ml}$, this concentration having been previously shown to be maximally effective in inducing $11 \beta \mathrm{HSD} 1 \mathrm{mRNA}$ expression and activity in OSE cells cultured in the same way (Yong et al. 2002). Cortisol and progesterone (stored as $100 \mu \mathrm{M}$ stock solutions in ethanol) were added to culture medium at a final concentration of $1 \mu \mathrm{M}$. Control culture medium received a similar dilution $(1 \% \mathrm{v} / \mathrm{v})$ of ethanol alone. The incubation was done for $48 \mathrm{~h}$ at $37^{\circ} \mathrm{C}$, whereupon media were aspirated and the cell monolayers processed as described below.

\section{Immunohistochemistry}

Following methanol fixation and triplicate 3-min washes in PBS, cell monolayers were sequentially blocked with avidin (Vector, Peterborough, UK), biotin (Vector) and non-immune serum (horse, Vector). Primary monoclonal antibodies for human GR (Santa Cruz Biotechnology Inc., Heidelberg, Germany), cytokeratin or PR (Dako Corp., Glostrup, Denmark), diluted $1 / 100,1 / 1000$ and $1 / 50$ respectively were applied for $1 \mathrm{~h}$ at $37^{\circ} \mathrm{C}$. After three washes with PBS $+0 \cdot 01 \%$ Tween 20 (Sigma-Aldrich; 3 min each), secondary antibody (horse-antimouse) diluted in non-immune horse serum was applied for $1 \mathrm{~h}$ at room temperature. Sequential washes with PBS $+0 \cdot 01 \%$ Tween $20(3 \times 3 \mathrm{~min})$ were then performed before incubating with Vector-ABC Elite reagents and visualisation via chromagen (diaminobenzidine) staining. Negative controls consisted of non-immune mouse IgG2 substituted for primary antiserum.

\section{$R N A$ extraction and quality analysis}

Total RNA was extracted using RNEasy Minispin columns (Qiagen) as per the manufacturer's instructions. RNA was quantified and quality assessed by microfluidic analysis (Agilent 2100 bioanalyser, Agilent technologies, Cheshire, UK).

\section{Quantitative RT-PCR analysis}

DNAseI-treated total RNA (200 ng) was reverse-transcribed to cDNA (random hexamer kit, Applied Biosystems, Warrington, Cheshire, UK) and $2 \mu \mathrm{l}$ resultant cDNA was analysed per reaction. The reaction mixture $(25 \mu \mathrm{l})$ consisted of $200 \mathrm{nmol} / 1$ probe and $300 \mathrm{nmol} / 1$ primers and was analysed using the ABI Prism 7900 real-time PCR system (Applied Biosystems). Primer and probe sequences have been reported previously (Rae et al. 2004). Target mRNA was quantified in relation to the abundance of $18 \mathrm{~S}$ rRNA in each sample. Controls included human liver, RT negative (RNA template but lacking reverse transcriptase), RT no template control (water instead of RNA template) and a Taqman step negative control (water instead of cDNA).

\section{1-Oxoreductase assay}

11-Oxoreductase activity was determined by measuring the conversion of $\left[1,2,6,7-{ }^{3} \mathrm{H}\right]$ cortisone to $\left[1,2,6,7-{ }^{3} \mathrm{H}\right]$ cortisol, as described previously (5). Briefly, each culture well received $0.5 \mathrm{ml}$ serum-free culture medium containing $0.1 \mu \mathrm{Ci}$ $\left[1,2,6,7-{ }^{3} \mathrm{H}\right]$ cortisone and $50 \mathrm{pmol}$ carrier cortisone (total substrate concentration $0 \cdot 1 \mu \mathrm{M}$ ). Incubation was for $8 \mathrm{~h}$ at $37^{\circ} \mathrm{C}$. The medium was then aspirated and vortexed with $5 \mathrm{ml}$ dichloromethane to extract steroids. The organic phase was then collected and evaporated to dryness under a stream of nitrogen. Dry steroid extracts were reconstituted in fresh dichloromethane and spotted onto silica gel precoated aluminium sheets (Sigma-Aldrich) for the separation of cortisone and cortisol by thin layer chromatography, using chloroform:ethanol $(92: 8 \mathrm{v} / \mathrm{v})$ as the solvent system. Radiolabelled steroids on the chromatogram were located and quantified using a Bioscan 200 imaging detector (Lablogic Systems, Sheffield, UK).

\section{Statistical analysis}

Quantitative RT-PCR measurements were normalised to the control (no treatment) value for each mRNA measured. Data from multiple patients (see figure legends) were grouped and expressed as mean \pm s.e.m. Statistical differences due to treatment were determined by repeated measures ANOVA of raw data reflecting the mean $C_{\mathrm{T}}$ difference between $18 \mathrm{~S}$ rRNA and target mRNA. The mean 11-oxoreductase enzymatic activity expressed as pmol/culture per $\mathrm{h}$ was compared between treated and untreated samples of the same cell type using paired Student's $t$-tests, and between OSE and 
PSE samples using unpaired Student's t-tests. Treatment effects were considered significant at $P<0 \cdot 05$.

\section{Results}

PSE cell morphology

The morphology of PSE cells in culture and their responses to experimental treatment in vitro were unaffected by the site within the abdominal cavity from which they had been obtained (data not shown). Sheets of PSE cells collected into culture medium usually attached to the serum-coated flask surface within $48 \mathrm{~h}$. Further incubation allowed multiple epithelial cell colonies to become established, eventually producing confluent monolayers. The 'cobblestone' morphology (Fig. 1a) and the mode of cytokeratin expression (Fig. 1b) shown by cultured PSE cells was similar to that previously described for OSE cells cultured in the same way (Hillier et al. 1998). Flasks that became contaminated by cells showing a fibroblastic phenotype were excluded from experimentation. Overall, out of the 29 patient PSE specimens collected, $21(72 \cdot 4 \%)$ produced cultures suitable for further study.

\section{PSE cell steroid receptor status}

PSE cell monolayers contained GR and PR mRNA levels similar to those present in OSE cells cultured under identical conditions (data not shown). Immunostaining with antisera to GR (Fig. 1c) or PR (Fig. 1d) revealed the presence of both the steroid receptor proteins in PSE cells, with a predominantly nuclear location.

\section{PSE cell responses to $I L-1 \alpha$ and cortisol}

To determine influences of IL- $1 \alpha$ and cortisol on inflammationassociated gene expression in PSE cells, we assessed 11 $\beta$ HSD1, $11 \beta \mathrm{HSD} 2$ and COX-2 mRNA levels, reasoning that the $11 \beta$ HSD isoform expression profile defines the potential for intracrine generation of anti-inflammatory cortisol, while COX-2 provides a referent inflammatory readout.

The treatment of PSE cell cultures from five patients with IL- $1 \alpha$ significantly increased the expression of $11 \beta$ HSD1 mRNA relative to non-treated control values (mean fold induction, 9.75, $P<0 \cdot 01$; Fig. 2a). PSE cells sampled from the anterior abdominal wall and the uterine serosal surface responded similarly to IL- $1 \alpha$ (average fold induction, 10.4 and $9 \cdot 0$ respectively). Cortisol alone also up-regulated $11 \beta \mathrm{HSD} 1$ mRNA expression 12.6-fold $(P<0 \cdot 001)$. In combination, cortisol and IL- $1 \alpha$ synergised to increase $11 \beta$ HSD1 expression 67.9-fold relative to the control $(P<0 \cdot 001)$.

Neither IL- $1 \alpha$ nor cortisol, alone or in combination, significantly affected $11 \beta \mathrm{HSD} 2 \mathrm{mRNA}$ expression (Fig. 2b).

The exposure to IL- $1 \alpha$ stimulated COX-2 mRNA expression on average was $10 \cdot 6$-fold $(P<0 \cdot 001$; Fig. 2 c).
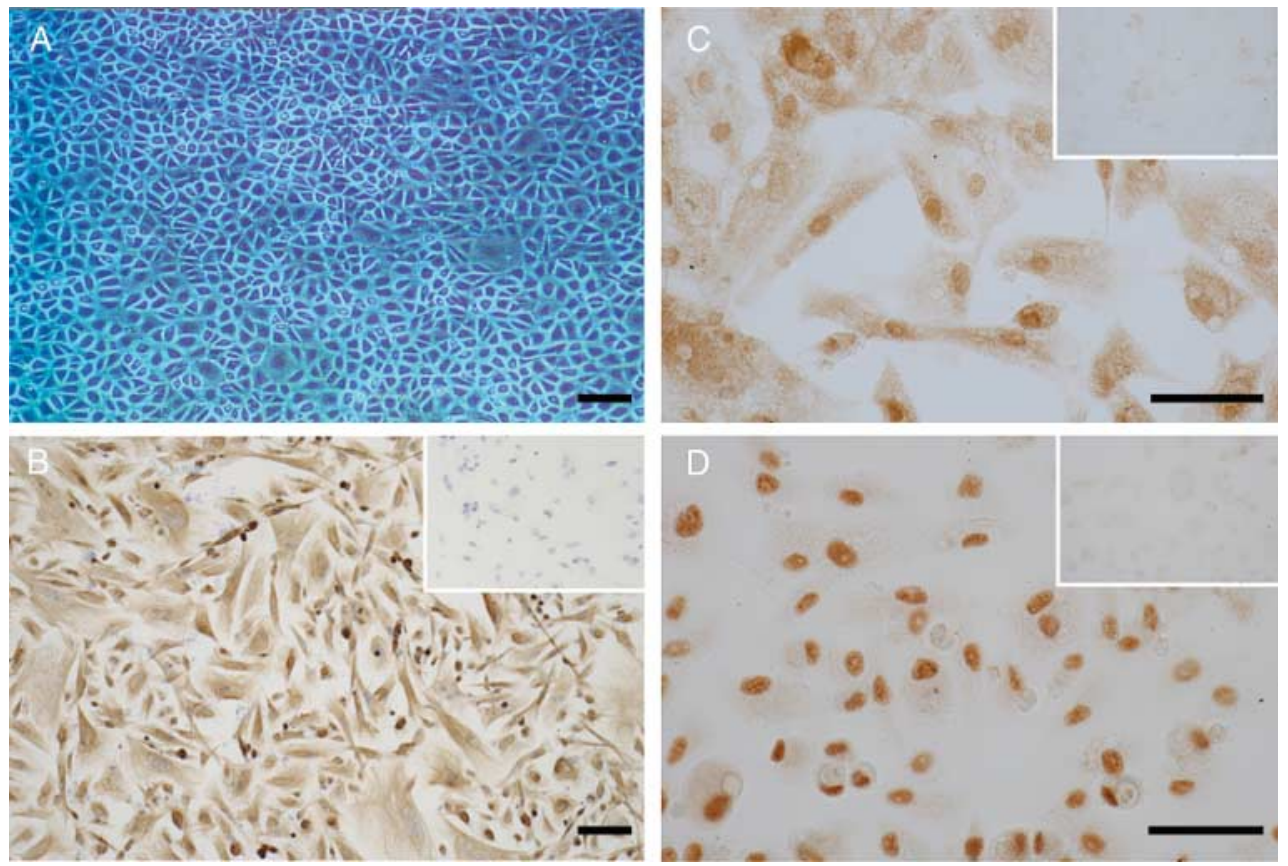

Figure 1 Morphology and immunohistochemical properties of cultured human PSE cells. (A) Phase-contrast microscopy of PSE cell monolayer on day 12 of culture following collection. (B) Cytokeratin immunohistochemistry using antiserum against a panel of low MW cytokeratins confirms epithelial phenotype of cultured PSE cells and purity of cell culture. (C) Glucocorticoid receptor (GR) and (D) progesterone receptor (PR) immunohistochemistry detect each receptor protein in PSE cell nuclei. Insets in B-D show matched non-immune control staining. Bars represent $100 \mu \mathrm{m}$. 

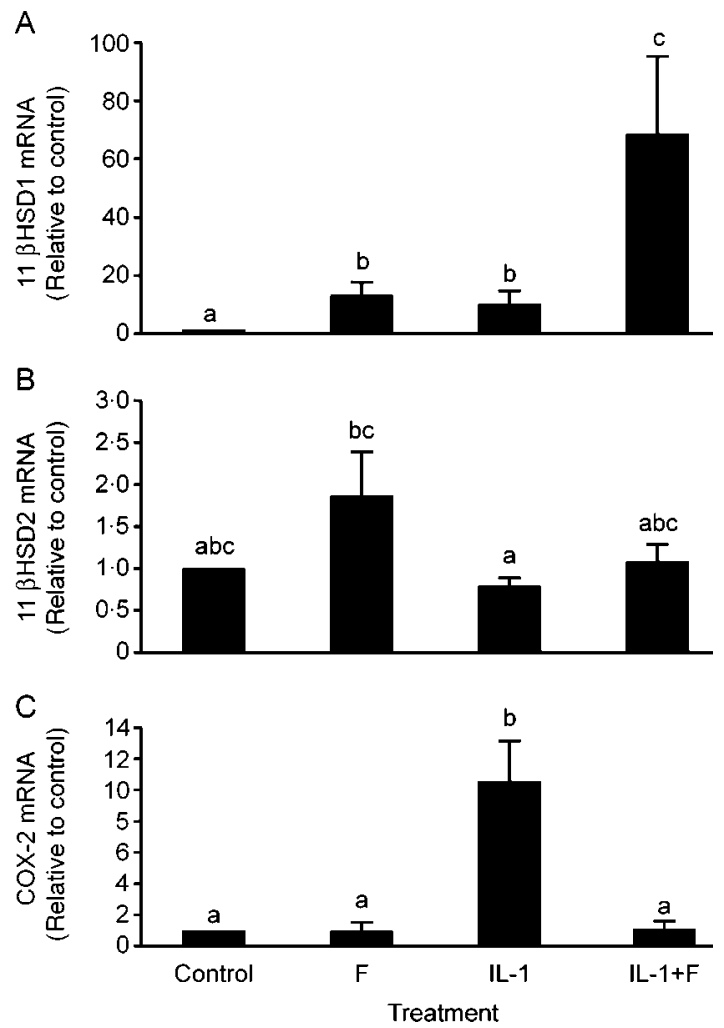

Figure 2 Interaction between interleukin- $1 \alpha$ (IL- $1 \alpha)$ and cortisol $(\mathrm{F})$ on inflammation-associated gene expression in PSE cells. Quantitative RT-PCR analysis of mRNA for (A) 11ßHSD1, (B) 11ßHSD2 and (C) COX-2 following treatment with IL-1 $\alpha(0.5 \mathrm{ng} / \mathrm{ml})$ and/or $\mathrm{F}(1 \mu \mathrm{M})$. Bars represent mean (+ S.E.M.) values relative to untreated control for PSE cell cultures from five individual patients. Values with no superscript letter in common are statistically different from each other $(P<0 \cdot 01)$.

Again, there was no significant difference in the magnitude of response in relation to the site of cell sampling from within the same patient (data not shown). Cortisol alone had no significant effect on COX-2 mRNA expression. However, in combination with IL- $1 \alpha$, cortisol significantly suppressed the IL- $1 \alpha$-induced rise in COX-2 mRNA to near control levels $(P<0 \cdot 001)$.

\section{Anti-inflammatory actions of cortisol and progesterone compared}

PSE cell cultures from a further six patients were used to test the relative anti-inflammatory effects of cortisol and progesterone on inflammation-associated gene expression.

Stimulation of $11 \beta \mathrm{HSD} 1 \mathrm{mRNA}$ by IL- $1 \alpha$ alone (average 7.25-fold, $P<0 \cdot 001)$ was confirmed in PSE cell cultures from this second series of patients (Fig. 3a). Cortisol alone was also stimulatory (average 10 -fold, $P<0 \cdot 001$ ). However, progesterone was inactive (Fig. 3a). Once again, cortisol augmented IL-1 $\alpha$-stimulated $11 \beta \mathrm{HSD} 1 \mathrm{mRNA}$ expression (to an average fold induction, $28 \cdot 3 ; \quad P<0 \cdot 01)$. Co-treatment with progesterone and IL- $1 \alpha$ also consistently increased $11 \beta$ HSD1 mRNA expression beyond that caused by IL- $1 \alpha$ alone (average $11 \cdot 8$-fold) but this effect was not statistically significant.
A
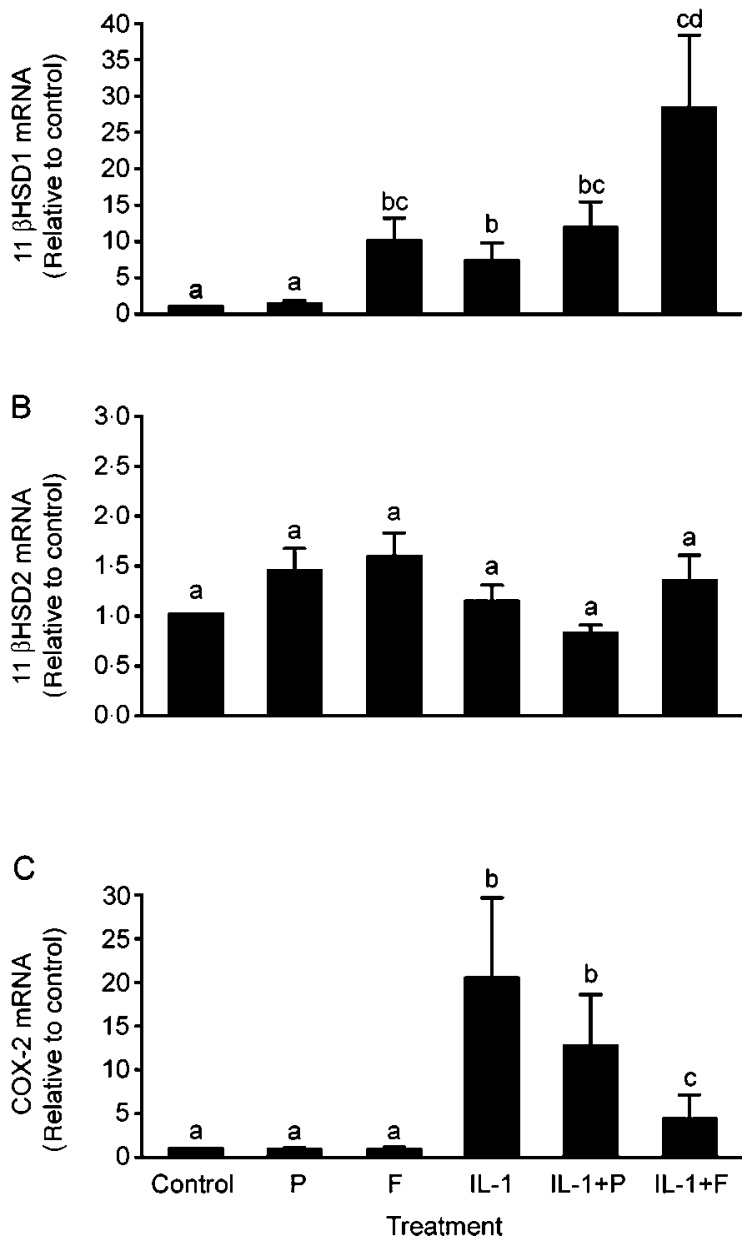

Figure 3 Comparison of the effects of cortisol (F) and progesterone (P) on inflammation-associated gene expression in PSE cells. Quantitative RT-PCR analysis of mRNA for (A) 11ßHSD1, (B) $11 \beta \mathrm{HSD} 2$ and $(\mathrm{C}) \mathrm{COX}-2$ following treatment with $\mathrm{F}(1 \mu \mathrm{M})$ or $\mathrm{P}$ $(1 \mu \mathrm{M})$ in the presence and absence of interleukin-1 $\alpha$ (IL-1 $\alpha$; $0.5 \mathrm{ng} / \mathrm{ml}$ ). Bars represent mean (+S.E.M.) values relative to untreated control for PSE cell cultures from six individual patients. Values with no superscript letter in common are statistically different from each other $(P<0 \cdot 01)$.

$11 \beta$ HSD 2 mRNA expression was unaffected by any of the treatments applied (Fig. 3b).

Stimulation of COX-2 mRNA by IL- $1 \alpha$ was strongly suppressed $(P<0 \cdot 001)$ by the presence of cortisol (average fold induction, $4 \cdot 5)$ and to a lesser extent $(P>0 \cdot 05)$ progesterone (average fold induction, 12·8; Fig. 3c).

\section{1-Oxoreductase enzymatic activity in PSE cells}

The finding that IL-1 $\alpha$ stimulates $11 \beta$ HSD1 mRNA expression in PSE cells predicts the up-regulation of 11-oxoreductase activity, as demonstrated previously in OSE cells (Yong et al. 2002). We therefore compared 
11-oxoreductase activity between cell types using PSE cultures from four patients (one of whom also provided an OSE culture for the comparison) and OSE cultures from three others. As shown in Fig. 4, the mean rate of conversion of cortisone to cortisol was significantly less in PSE compared with OSE, under both control $(0 \cdot 14 \mathrm{picomol} / \mathrm{culture}$ per $\mathrm{h}$ versus $0.93 \mathrm{picomol} /$ culture per $\mathrm{h}, P<0.05)$ and IL-1 $\alpha(0.33$ picomol/culture per h versus 1.56 picomol/culture per $h$, $P<0 \cdot 05)$ treatment conditions. Although exposure to IL-1 $\alpha$ consistently raised 11-oxoreductase activity in both OSE and PSE cells, only the effect on OSE cells was statistically significant.

\section{Discussion}

We show that the cells lining the human peritoneum are able to up-regulate $11 \beta \mathrm{HSD} 1$ gene expression in response to the inflammatory cytokine IL-1 $\alpha$ in vitro. Furthermore, cortisol the product of 11-oxoreductase activity catalysed by $11 \beta \mathrm{HSD} 1$ - is anti-inflammatory in PSE cells. Basal and IL$1 \alpha$-stimulated 11-oxoreductase enzymatic activity in PSE cells is, however, substantially weaker than that of closely related OSE cells. Thus, we provide mechanistic insight on anti-inflammatory signalling in human peritoneum and establish differences between OSE and PSE cells that could help explain the relative susceptibility of PSE to adhesion formation following inflammation-associated injury in vivo.

Human PSE cells have previously been obtained from resected omentum (Stylianou et al. 1990, Pronk et al. 1993) or

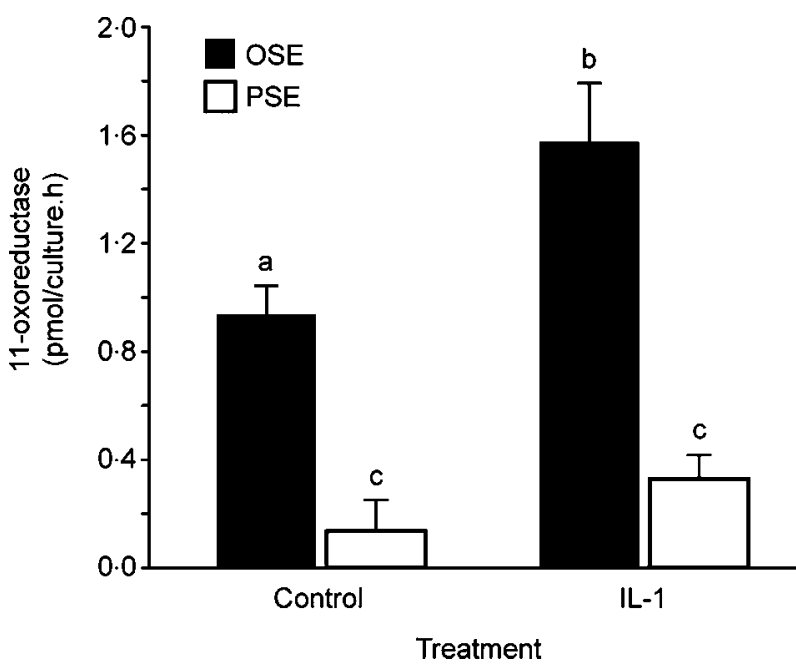

Figure 4 Comparison of 11-oxoreductase activity in PSE and OSE cells. 11-Oxoreductase activity in cultured cells was determined by radiometric assay (see Materials and Methods) following a 48-h incubation with or without interleukin- $1 \alpha$ (IL- $1 \alpha ; 0.5 \mathrm{ng} / \mathrm{ml})$. Bars represent mean ( + S.E.M.) values relative to untreated control for four patients (cultures), one of whom provided matched PSE and OSE. Values with no superscript letter in common are statistically different from each other $(P<0 \cdot 05)$. peritoneum (Witz et al. 1998) and cultured with varying success. Here, we swept up cells directly from peritoneal sites in situ, avoiding enzymatic tissue digestion to obtain pure mesothelial cell cultures. This atraumatic technique of PSE collection allows single-cell-thick sheets of cells to be cultured with the low likelihood of contamination by other cell types. Morphology of the PSE monolayer in vitro closely resembles the classic 'cobblestone' appearance of OSE cultured under similar conditions. The mesothelial origin of the PSE cultures we studied was also confirmed by the pattern of lowmolecular weight cytokeratin expression they showed, which is also similar to OSE (Auersperg et al. 2001) and increases confidence that the PSE cultures were not significantly contaminated with any other cell type.

PSE and OSE cells not only look alike but also share a similar biochemical signature in response to inflammation. Along with inflammation-associated COX-2 gene expression in response to IL- $1 \alpha$ they show up-regulation of $11 \beta$ HSD1 mRNA without any change in $11 \beta \mathrm{HSD} 2$. Whether any functional link exists between COX-2 and 11 $\beta$ HSD 1 mRNA expression in IL- $1 \boldsymbol{\alpha}$-stimulated PSE cells remains to be established. However, this is suggested by the finding that prostaglandin synthesis is required for the stimulation of $11 \beta$ HSD1 enzyme activity by IL-1 $\beta$ in human granulosalutein cell cultures (Jonas et al. 2006). PSE also has in common with OSE the feed-forward response of $11 \beta$ HSD1 when stimulated by IL- $1 \alpha$ in the presence of cortisol (Rae et al. 2004). This predicts the capacity to mount a compensatory increase in intracellular levels of cortisol in response to inflammatory stimulation in vivo.

Owing to the clinical basis of this study, insufficient patient material was available to delineate the post-receptor signalling mechanisms involved in the actions of IL- $1 \alpha$ and antiinflammatory steroids in PSE cells. However, we did document similar levels of mRNA for PR and GR, and clearly detected nuclear PR and GR proteins. In other experimental systems, nuclear GR and PR receptors transduce positive and negative regulation of genes that impact signalling via cell-surface receptors for pro-inflammatory cytokines (Rosen \& Milner 2005) and it is reasonable to suppose that these mechanisms operate in PSE cells too. Other caveats to our results include the extent to which pro-/anti-inflammatory properties of PSE and OSE cells propagated in vitro might deviate from norm in terms of functionality in vivo. Comparisons of 11-oxoreductase activities in PSE and OSE cell cultures from individual patients also proved problematic owing to a variable adaptation of individual cell biopsies to culture. However, we consistently observed a restricted capacity of PSE cells to undertake 11-oxoreductase activity relative to OSE cells. Moreover, for the single patient from whom both PSE and OSE cell cultures were available for direct comparison, the result obtained (embedded within the data set in Fig. 4) faithfully mirrored the aggregate outcome.

The physiological significance of these results is that cytokine-responsive $11 \beta$ HSD 1 could provide a mechanism throughout the peritoneal surface to localise and limit 
inflammation-associated injury and promote rapid healing of traumatised tissue through pre-receptor amplification of cortisol formation. However, 11ßHSD1 enzyme activity in PSE is lower than that in OSE, indicating that the ovary is better protected by anti-inflammatory mechanisms than the peritoneum. The higher 11-oxoreductase tone of OSE, if reflected in higher local cortisol levels in vivo, might be sufficient to minimise fibrosis and thereby reduce the likelihood of postovulatory adhesions. This is borne out by the fact that the ovaries remain mobile and free within the pelvis of most women. On the other hand, the peritoneum is a more stable environment, less prone to natural injury and with a lower 11-oxoreductase tone than the ovarian surface. The sporadic injuries that do occur to PSE tend to be iatrogenic - e.g. during surgery - or involve microbial infection and are inherently more traumatic. This indicates that downstream pro-inflammatory sequelae likely override any compensatory anti-inflammatory benefit arising from $11 \beta$ HSD 1 signalling, permitting fibrosis and adhesion formation to proceed.

Progesterone, present at high concentrations in follicular fluid at the time of ovulation (Andersen \& Hornnes 1994), is a candidate anti-inflammatory agent throughout the pelvic cavity. However, progesterone was considerably less potent than cortisol as an anti-inflammatory agent in cultured PSE, matching our previous finding for OSE (Rae et al. 2004). Nevertheless, $1 \mu \mathrm{M}$ progesterone reduced IL- $1 \alpha$-stimulated COX-2 mRNA expression $37 \%$, on average, in $6 / 6$ cases (Fig. 3). Although this effect was statistically non-significant, it may yet be biologically important since progesterone levels in follicular fluid can attain levels up to 30 times higher than those tested here. Accordingly, we do not rule out the possibility that progesterone exerts a physiologically significant action on OSE and/or PSE cells during ovulation in vivo. The responsiveness of PSE cells to progesterone also has broader clinical relevance. First, it raises the possibility that the peritoneum may be affected by menstrual fluctuations in ovarian progesterone secretion. Secondly, it is relevant to endometriosis where withdrawal of progesterone prior to menstruation coincides with the most severe symptoms. Thirdly, exogenous progestin is a mainstay treatment for endometriosis.

Finally, our results may have a bearing on the development of epithelial ovarian cancer (EOC). The OSE is widely regarded as the major source of most ovarian cancers (Fleming et al. 2006) and EOC frequently involves other peritoneal structures, hence its overall poor outcome (Freedman et al. 2004). However, the natural history of EOC is not well defined. This is partly due to the fact that patients most commonly present with advanced stage disease with widespread peritoneal and omental involvement. This in turn makes curative treatment difficult leading to poor survival outcomes of $30 \%$ at 5 years. If the disease could be contained within the ovary at FIGO (International Federation of Gynaecology and Obstetrics) stage I, an improvement in prognosis would be expected to follow. Therefore, manipulation of the tumour-peritoneum interaction is a potential therapeutic strategy. Progesterone has been suggested as a potential chemopreventative agent for EOC and lack of progesterone may have pathophysiological roles for both endometriosis and ovarian cancer (Ho 2003, Ness 2003).

In summary, we demonstrate a simple method for the collection and culture of human PSE cells. Using this culture system, we find that PSE cells possess an anti-inflammatory machinery similar to that previously described for OSE cells, including a capacity to up-regulate $11 \beta \mathrm{HSD} 1$ in response to treatment with IL- $1 \alpha$. However, enzymatic activity of 11-oxoreductase is lower in PSE than in OSE. Although the cause for this difference remains unknown, our data provide a possible explanation for the observation that peritoneal healing is often accompanied by adhesion formation, while ovulationassociated ovarian healing is scarless.

\section{Acknowledgements}

We are grateful to Ms Deborah Price for skilled technical support and to Ms Catherine Murray and Mrs Sharon Donaldson for help with tissue collection. This work forms part of a $\mathrm{PhD}$ thesis submitted by K S F to the University of Edinburgh. This research was supported by MRC Programme Grant G0500047 (S G H and H O D C) and a Cancer Research UK Clinical Training Fellowship (K S F). There is no conflict of interest that would prejudice the impartiality of this study.

\section{References}

Andersen CY 1991 Concentrations of free oestradiol and progesterone in human preovulatory follicular fluid. Human Reproduction 6 359-364.

Andersen CY \& Hornnes P 1994 Intrafollicular concentrations of free cortisol close to follicular rupture. Human Reproduction 9 1944-1949.

Auersperg N, Wong AS, Choi KC, Kang SK \& Leung PC 2001 Ovarian surface epithelium: biology, endocrinology, and pathology. Endocrine Reviews 22 255-288.

van der Burg B \& van der Saag PT 1996 Nuclear factor- $\kappa-B /$ steroid hormone receptor interactions as a functional basis of anti-inflammatory action of steroids in reproductive organs. Molecular Human Reproduction 2 433-438.

Cai T-Q, Wong B, Mundt SS, Thieringer R, Wright SD \& HermanowskiVosatka A 2001 Induction of $11 \beta$-hydroxysteroid dehydrogenase type 1 but not -2 in human aortic smooth muscle cells by inflammatory stimuli. Journal of Steroid Biochemistry and Molecular Biology 77 117-122.

Cooper MS, Bujalska I, Rabbitt E, Walker EA, Bland R, Sheppard MC, Hewison M \& Stewart PM 2001 Modulation of 11beta-hydroxysteroid dehydrogenase isozymes by proinflammatory cytokines in osteoblasts: an autocrine switch from glucocorticoid inactivation to activation. Journal of Bone and Mineral Research 16 1037-1044.

Draper N \& Stewart PM 2005 11beta-hydroxysteroid dehydrogenase and the pre-receptor regulation of corticosteroid hormone action. Journal of Endocrinology 186 251-271.

Escher G, Galli I, Vishwanath BS, Frey BM \& Frey FJ 1997 Tumor necrosis factor alpha and interleukin 1beta enhance the cortisone/cortisol shuttle. Journal of Experimental Medicine 186 189-198.

Feinstein MB \& Schleimer RP 1999 Regulation of the action of hydrocortisone in airway epithelial cells by 11 beta-hydroxysteroid dehydrogenase. American Journal of Respiratory Cell and Molecular Biology 21 403-408. 
Fleming JS, Beaugie CR, Haviv I, Chenevix-Trench G \& Tan OL 2006 Incessant ovulation, inflammation and epithelial ovarian carcinogenesis: revisiting old hypotheses. Molecular and Cellular Endocrinology 247 4-21.

Freedman RS, Deavers M, Liu J \& Wang E 2004 Peritoneal inflammation - a microenvironment for epithelial ovarian cancer (EOC). Journal of Translational Medicine 223

Gilmour JS, Coutinho AE, Cailhier JF, Man TY, Clay M, Thomas G, Harris HJ, Mullins JJ, Seckl JR, Savill JS et al. 2006 Local amplification of glucocorticoids by 11 beta-hydroxysteroid dehydrogenase type 1 promotes macrophage phagocytosis of apoptotic leukocytes. Journal of Immunology 176 7605-7611.

Hillier SG, Anderson RA, Williams AR \& Tetsuka M 1998 Expression of oestrogen receptor alpha and beta in cultured human ovarian surface epithelial cells. Molecular Human Reproduction 4 811-815.

Ho SM 2003 Estrogen, progesterone and epithelial ovarian cancer. Reproductive Biology and Endocrinology 173.

Jonas KC, Chandras C, Abayasekara DR \& Michael AE 2006 Role for prostaglandins in the regulation of type 111 beta-hydroxysteroid dehydrogenase in human granulosa-lutein cells. Endocrinology 147 5865-5872.

Li W, Gao L, Wang Y, Duan T, Myatt L \& Sun K 2006 Enhancement of cortisol-induced $11 \beta$-hydroxysteroid dehydrogenase type 1 expression by interleukin $1 \beta$ in cultured human chorionic trophoblast cells. Endocrinology $1472490-2495$.

Ness RB 2003 Endometriosis and ovarian cancer: thoughts on shared pathophysiology. American Journal of Obstetrics and Gynecology 189 280-294.

Pronk A, Leguit P, Hoynck van Papendrecht AA, Hagelen E, van Vroonhoven T] \& Verbrugh HA 1993 A cobblestone cell isolated from the human omentum: the mesothelial cell; isolation, identification, and growth characteristics. In Vitro Cellular and Developmental Biology: Journal of the Tissue Culture Association 29A 127-134.

Rae MT \& Hillier SG 2005 Steroid signalling in the ovarian surface epithelium. Trends in Endocrinology and Metabolism 16 327-333.

Rae MT, Niven D, Critchley HO, Harlow CR \& Hillier SG 2004 Antiinflammatory steroid action in human ovarian surface epithelial cells. Journal of Clinical Endocrinology and Metabolism 89 4538-4544.
Rhen T \& Cidlowski JA 2005 Antiinflammatory action of glucocorticoids new mechanisms for old drugs. New England Journal of Medicine 353 1711-1723.

Rosen J \& Miner JN 2005 The search for safer glucocorticoid receptor ligands. Endocrine Reviews 26 452-464.

Stylianou E, Jenner LA, Davies M, Coles GA \& Williams JD 1990 Isolation, culture and characterization of human peritoneal mesothelial cells. Kidney International 37 1563-1570.

Sun K \& Myatt L 2003 Enhancement of glucocorticoid-induced 11betahydroxysteroid dehydrogenase type 1 expression by proinflammatory cytokines in cultured human amnion fibroblasts. Endocrinology 144 5568-5577.

Tetsuka M, Thomas FJ, Thomas MJ, Anderson RA, Mason JI \& Hillier SG 1997 Differential expression of messenger ribonucleic acids encoding 11beta-hydroxysteroid dehydrogenase types 1 and 2 in human granulosa cells. Journal of Clinical Endocrinology and Metabolism 82 2006-2009.

Tetsuka M, Haines LC, Milne M, Simpson GE \& Hillier SG 1999 Regulation of 11beta-hydroxysteroid dehydrogenase type 1 gene expression by $\mathrm{LH}$ and interleukin-1beta in cultured rat granulosa cells. Journal of Endocrinology 163 417-423.

Tomlinson JW, Moore J, Cooper MS, Bujalska I, Shahmanesh M, Burt C, Strain A, Hewison M \& Stewart PM 2001 Regulation of expression of 11beta-hydroxysteroid dehydrogenase type 1 in adipose tissue: tissuespecific induction by cytokines. Endocrinology 142 1982-1989.

Witz CA, Montoya-Rodriguez IA, Miller DM, Schneider BG \& Schenken RS 1998 Mesothelium expression of integrins in vivo and in vitro. Journal of the Society for Gynecologic Investigation 5 87-93.

Yong PY, Harlow C, Thong KJ \& Hillier SG 2002 Regulation of 11betahydroxysteroid dehydrogenase type 1 gene expression in human ovarian surface epithelial cells by interleukin-1. Human Reproduction 17 2300-2306.

Received in final form 25 October 2007

Accepted 2 November 2007

Made available online as an Accepted Preprint 2 November 2007 